Volume 9, No.1.3, 2020

International Journal of Advanced Trends in Computer Science and Engineering

Available Online at http://www.warse.org/IJATCSE/static/pdf/file/ijatcse5991.32020.pdf

https://doi.org/10.30534/ijatcse/2020/5991.32020

\title{
Fuzzy Knowledge to Detect Imprecisions in Strategic Decision Making in a Smart Port
}

\author{
C. Durán ${ }^{1, *}$, F. Córdova ${ }^{2}$, F. Yanine ${ }^{3}$, E. Carrillo ${ }^{4}$ \\ ${ }^{1}$ Faculty of Engineering Department of Industry, Universidad Tecnológica Metropolitana, José Pedro Alessandri \\ 1242, Nuñoa, Santiago, Chile, c.durans@utem.cl \\ ${ }^{2}$ Faculty of Engineering, University Finis Terrae, Avda. Pedro de Valdivia 1509, Providencia, Santiago, Chile, \\ fcordova@uft.cl \\ ${ }^{3}$ Faculty of Engineering, Universidad Finis Terrae, Av. Pedro de Valdivia 1509, Providencia; Santiago, Chile, \\ fyanine@uft.cl \\ ${ }^{4}$ Department of Industry, Universidad Tecnológica Metropolitana, José Pedro Alessandri 1242, Ñuñoa, Santiago, \\ Chile, eduardo.carrillol@utem.cl
}

\begin{abstract}
Port enterprises usually declare ambiguous strategic phrases which frequently lack of information related to the multi-criteria in their economic/ social/ technological/ environmental/ risk/ learning macro-environment. It is necessary that every actor includes these factors in his/her statements in order that the strategic and business decision-making be efficient by including the demands for investing in intelligent assets. In this study, taking into account the strategic information and the opinion of experts of a port system, fuzzy relationships of cause-effect between the critical factors of strategic success and the Cyber-Social-Technological-Cognitive domains of the conceptual model (CSTC) will be determined for a smart port. The valuation matrixes of first and second order are developed, the results are analysed and some suggestions are addressed to the Port Community and logistics companies.
\end{abstract}

Key words : Strategic Decision Making; Expert Asset; Bsc; Fuzzy Knowledge.

\section{INTRODUCTION}

Systems composed of private companies and public organizations, being part of a logistics chain that provides services in an industrial sector, are complex to study [1], since every component shows different strategic and business characteristics. Nevertheless, those processes linked to productive activities are demanded to be efficient and effective to increase their competitiveness [2][3].

A port can be seen as a logistics network where there are cargo, money and information flows among each and every actor, who at the same time are related with different aspects of the political /economic/ social/ technological/ environmental/risk/learning macro-environment [3][4] and internal factors regarded as important for business, such as: infrastructure, logistics chains configuration, industry production, management of every area and services provision to cover demands [4]. The Port Community, comprised of the Port Administrator and terminals, follows a country plan where the State establishes the strategic guidelines concerning with investment of new assets in order to: improve the port-city relationship [5], have a more friendly relationship with the environment [6], be more profitable [3], automatize operation areas [7], increase the communication and information technology [8], among others.

The decision-making process in a company system where strategic and business statements show imprecise multi-criteria may become complex [9], due to the lack of alignment between the mission and actions of every actor. The management tool Balanced Scorecard, experts' opinion and fuzzy knowledge, were used to study, concerning the strategic attributes, the cause-effect fuzzy relationships between the critical factors of success and the indicators representing and assessing the business actions of a Port Community [10][11].

The present work focuses on the strategic phrases expressed in the missions of an intelligent port system in search for the possible relationship between the investment level in technology and the critical factors of success declared in their strategic and business information. Our attention will be paid on the assets identified as necessary for generating projects of disruptive technology and advanced digital transformation systems related with data, information and knowledge flow and real-time events control [12], in the hyperspace domain of the Cyber-Social-Technological-Cognitive conceptual model (CSTC) [13].

\section{STRATEGIC IMPRECISION IN A CHILEAN PORT}

\subsection{Strategic and business fuzzy relationships}

Our object of study are the strategic phrases from some private actors performing the activity of administrator and/or 
C. Durán et al., International Journal of Advanced Trends in Computer Science and Engineering, 9(1.3), 2020, 377 - 380

carrying out the logistics operations of a generic medium-size public port system, granted under concession to private enterprises [3]. In Table 1, critical factors of success (mandatory strategic and business generic attributes) are displayed, that could be related to the multi-criteria of the economic, social, technological, environmental, risk and learning macro-environment and to the investment decisions in assets to meet the demands of an intelligent, fifth generation port which is focused on technological aspects and on their customers' integration with the city [6][7][13]. It is worth noting that there are foreign actors whose mission and objectives are more linked of an intelligent port than local actors operating in Chile.

Table 1: Classification of critical strategic and business success factors

\begin{tabular}{|c|c|}
\hline Enterprises & Critical Success Factors \\
\hline $\begin{array}{ll}\text { Port } & \text { Community } \\
\left(C_{1}\right) & \end{array}$ & $\begin{array}{ll}\text { Improvement of logistics and } \\
\text { infrastructure conditions } \\
\text { Good practices } \\
\text { Technical Innovation } \\
\text { Increase port-city relationships }\end{array}$ \\
\hline $\begin{array}{l}\text { Dockage } \\
\left(\mathrm{C}_{2}\right)\end{array}$ & $\begin{array}{l}\text { More efficient service and logistics } \\
\text { operations } \\
\text { Commitment with the city } \\
\text { Innovation in their processes }\end{array}$ \\
\hline $\begin{array}{l}\text { Storage and } \\
\text { containers } \\
\text { management } \\
\text { service }\left(C_{3}\right)\end{array}$ & $\begin{array}{l}\text { State-of-the-art technologies in their } \\
\text { processes } \\
\text { Systematization of customer service } \\
\text { functions } \\
\text { Improvements in the work system }\end{array}$ \\
\hline $\begin{array}{l}\text { Land transport } \\
\text { enterprise }\left(\mathrm{C}_{4}\right)\end{array}$ & $\begin{array}{l}\text { Provide added value to their services } \\
\text { Technological innovation } \\
\text { Greater development in intelligent } \\
\text { technologies } \\
\text { Logistics knowledge }\end{array}$ \\
\hline
\end{tabular}

As presented in Figure 1, an intelligent port may be classified according to the amount of assets holding in each domain of the CSTC model [13]. When comparing the level of accomplishment of the cyber-social-technological-cognitive assets to every critical factor of success in every company of the Port Community, a diffused cause-effect link is observed because for decision making there is not a clear degree of incidence among the multi-criteria aspects due to the limited and ambiguous information at hand. These strategic phrases represent the fix current conditions which can be changed in the future, depending on the macro-environment conditions which may be uncertain. For instance: in periods with less economic activity in the country, investment in technological projects could be reduced, social movements and unions could stop their port activities, and the lack of advanced human capital could lower down fuzzy technology demands.

\subsection{Fuzzy Incidence first order matrix}

Incidence relationships of first order are expressed in a fuzzy matrix in Figure 2. In order to determine if each ordered pair $\left(\mathrm{x}_{\mathrm{i}}, \mathrm{x}_{\mathrm{j}}\right) \in \mathrm{R} \subset \mathrm{D} \times \mathrm{C}$ and the subset is defined according to the fuzzy membership function [14] associated to the fuzzy set:

$\mathrm{S}=\left\{\left(\mathrm{x}, \mu_{S}(x)\right) / x \in S\right\}$ where $\mu_{S}: X \longrightarrow[0,1][15]$

Given the referential subsets:

$\mathrm{D}=\left\{\mathrm{D}_{1}, \mathrm{D}_{2}, \mathrm{D}_{3}, \mathrm{D}_{4}\right\}, \mathrm{C}=\left\{\mathrm{C}_{1}, \mathrm{C}_{2}, \mathrm{C}_{3}, \mathrm{C}_{4}\right\}$

To value each fuzzy element of matrix $\mathrm{S}$, a semantic equivalent is used that relates a value scale to the degree of incidence assigned. This is displayed in Table 2.

Table 2: Diffuse valuation scale

\begin{tabular}{cl}
\hline Value & \multicolumn{1}{c}{ Semantics } \\
\hline 0 & Without incidence \\
0.1 & Practically without incidence \\
0.2 & Almost without incidence \\
0.3 & Very weak incidence \\
0.4 & Weak incidence \\
0.5 & Medium incidence \\
0.6 & Sensitive incidence \\
0.7 & Sufficient incidence \\
0.8 & Strong incidence \\
0.9 & Very strong incidence \\
1 & Total incidence \\
\hline
\end{tabular}

Smart port system domains (CSTC model)

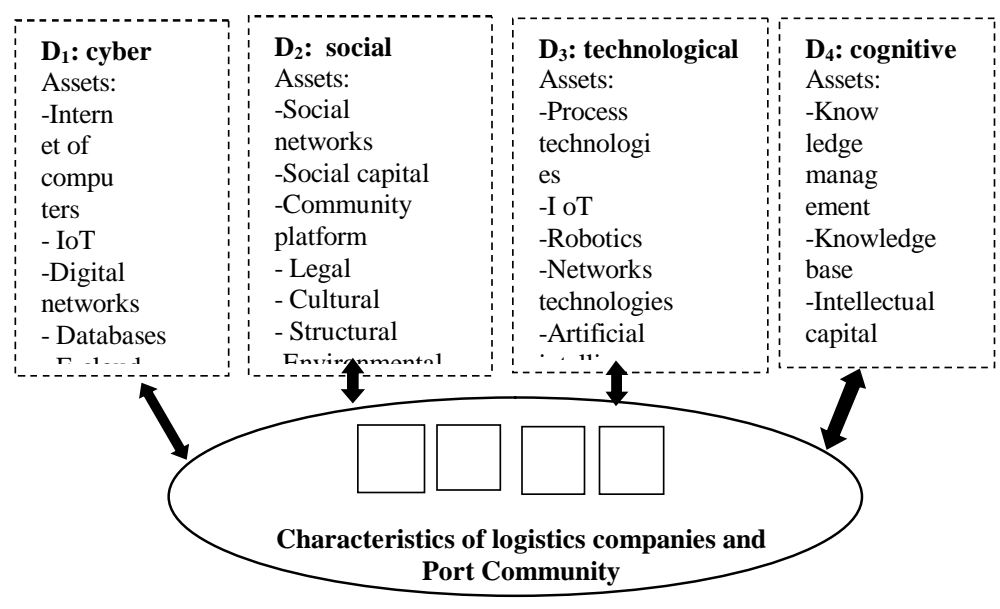

Figure 1: Fuzzy relationships in the port domain.

To identity the cause-effect fuzzy relationships that have not been foreseen and considered in decision-making, it is necessary to use the average obtained in Table 2 from the answers of three expert seniors from two Chilean ports and the information concerning to the existing gaps between Chilean ports and an intelligent port [13]. Then, Matlab tool generates the fuzzy matrix of qualitative incidence of first order $\mathrm{S}$ and the fuzzy clustering analysis that is shown in Figure $2[15,16]$. 
C. Durán et al., International Journal of Advanced Trends in Computer Science and Engineering, 9(1.3), 2020, 377 - 380

To calculate the Fuzzy c-means, 99 iterations are realized and the target function is used:

$\mathrm{J}_{\mathrm{m}}=\sum_{i=1}^{N} \Sigma_{j=1}^{M} \mu_{i j}^{k}\left\|x_{i} \quad m_{j}\right\|^{2}, \quad 1 \leq \mathrm{k} \leq \infty$

With $\mathrm{N}=$ number of data, $\mathrm{M}=$ number of clusters, $\mathrm{k}=$ controls the degree of diffused superposition, $x_{i}=$ data $i, m_{j}=$ cluster $j$ center, $\mu_{\mathrm{ij}}=$ membership degree of $\mathrm{x}_{\mathrm{i}}$ in cluster $\mathrm{j}$.

\begin{tabular}{|c|c|c|c|c|c|c|c|c|}
\hline Row ID & $D C 1$ & $D C 2$ & $D C 3$ & $D C 4$ & D duster_o & D duster_1 & D duster_2 & S Winner ... \\
\hline$D 1$ & 0.8 & 0.4 & 0.4 & 0.7 & I & I & 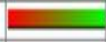 & duster_2 2 \\
\hline 02 & 0.3 & 0.1 & 0.2 & 0.3 & $\square$ & & 1 & duster_o \\
\hline D3 & 0.4 & 0.4 & 0.1 & 0.2 & 1 & 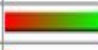 & & duster_! \\
\hline D4 & 0.2 & 0.2 & 0.1 & 0.4 & $\square$ & I & 1 & duster_o \\
\hline
\end{tabular}

Figure 2: Value matrix of first order $\mathrm{S}$

\subsection{Fuzzy matrix of the second order}

To determine the missing elements not expressed by experts, a process of max-min convolution in the square matrix $\mathrm{S}$ is realized [14], by multiplying rows by columns:

$\mu(\mathrm{Di}, \mathrm{Dk})=\max _{j}(\mathrm{mín}(\mu(\mathrm{Di}, \mathrm{Cj}), \mu(\mathrm{Cj}, \mathrm{Dk})))$

$\forall D i, C j \operatorname{con} i, j, k=1, \ldots, 4$

As displayed in Figure 3, Matlab is used to obtain matrix M and Fuzzy c-means with 99 iterations.

\begin{tabular}{|c|c|c|c|c|c|c|c|}
\hline Row ID & $D D 1$ & $D D 2$ & DD3 & DD4 & $D$ duster_ol & D duster_1 & S Wimer.... \\
\hline$D 1$ & 0.8 & 0.3 & 0.8 & 0.4 & 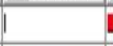 & \multicolumn{2}{|c|}{ duster_ 1} \\
\hline$D 2$ & 0.3 & 0.3 & 0.3 & 0.3 & إ & & duster_o \\
\hline D3 & 0.8 & 0.3 & 0.8 & 0.4 & I & & duster_1 \\
\hline 04 & 0.4 & 0.3 & 0.4 & 0.4 & ا & & duster_. 0 \\
\hline
\end{tabular}

Figure 3: Value Matrix of second order D

\section{DISCUSSIONS AND RESULTS}

In the incidence matrix of first order $\mathrm{S}$, it is observed that cluster 2 in cyber domain (D1) has the greatest values, while clusters 0 , social and cognitive aspects have the least. This mainly happens because their interest is focused both on their investment returns and on improving productivity, resulting in a lack of concern for the city-port relationship and the generation of new knowledge.

The incidence matrix of second order shows that cyber (D1) and technological (D3) factors have a strong incidence, mainly because of the incorporation of Internet, data bases, digital and platform networks in the port and Port Community. The same is observed with the integration of service and process technologies, and cyber security. Also, the mutual influence of these two factors (D1 and D3) is perceived, above all other factors analysed by experts, showing that the port activity is becoming more technological and cyber space is taking a prominent place towards the smart port trend.

\section{CONCLUSION}

The imprecision of the strategic phrases found among the missions of private actors, turns them ambiguous, calling for the inclusion of some aspects from the economic/ social/ technological/ environmental/ risk/ learning macro-environment that are necessary to represent the strategic purpose of each individual organization and the corporation system as a whole. This lack of information affects decision-making since the critical factors of business and strategic success will show no demands of physical assets, information, and knowledge, needed for more efficient and effective productive processes.

In this work, the analysis involved the strategic phrases of a medium-size Chilean port system composed of private enterprises that administrate and provide logistics services to the port, in order to determine the critical factors of success that are related to the assets needed for a smart port. With the experts' opinion and the fuzzy knowledge, it was possible to find the existing cause-effect fuzzy relationships between the cyber, social, technological and cognitive domains and the strategic and business declarations.

In the results, it was noted that the highest incidence ratios are in the domains that are more related to investments in assets that directly improve short and medium term operations, this is mainly due to the fact that in Chile ports are beginning to incorporate disruptive technologies linked to industry 4.0, and the decision-makers are risk averse as they have a more reactive attitude to technological changes. As companies are concerned about obtaining benefits in the shortest possible time, there is a lower incidence in the domains most linked to human capital, culture and the environment.Finally, the second order valuation matrix helped validate the opinion of experts.

\section{ACKNOWLEDGEMENT}

Faculty of Engineering at Universidad Tecnológica Metropolitana and Faculty of Engineering at Universidad Finis Terrae.

\section{REFERENCES}

1. Irannezhad E, Hickman M and Prato C G. Modeling the efficiency of a port community system as an agent-based process. Procedia Computer Science, 2017, 109: 917-922 https://doi.org/10.1016/j.procs.2017.05.422

2. Carlan V, Sys C and Vanelslander T. How port community systems can contribute to port competitiveness: Developing a cost-benefit framework. Research in Transportation Business \& Management, 2016, 19: 51-64

3. Duran C A, Palominos F and Cordova F M. Applying multi-criteria analysis in a port system. Procedia computer science, 2017, 122: 478-485

https://doi.org/10.1016/j.procs.2017.11.396

4. Othman M K, Rahman N S, Ismail A and Saharuddin A H. Factors contributing to the imbalances of cargo flows in Malaysia large-scale minor ports using a fuzzy analytical hierarchy process (FAHP) approach. The Asian Journal of Shipping and Logistics, 2020

5. Galvao C B, Wang G W and Mileski J. (2016). Public-private interests and conflicts in ports: A content analysis approach. The Asian Journal of Shipping and 
C. Durán et al., International Journal of Advanced Trends in Computer Science and Engineering, 9(1.3), 2020, 377 - 380

Logistics, 2016, 32(1): 13-22

https://doi.org/10.1016/j.ajsl.2016.03.002

6. Jun W K, Lee M K and Choi J Y. Impact of the smart port industry on the Korean national economy using input-output analysis. Transportation Research Part A: Policy and Practice, 2018, 118: 480-493

7. Yang Y, Zhong M, Yao H, Yu F, Fu X and Postolache O. Internet of things for smart ports: Technologies and challenges. IEEE Instrumentation \& Measurement Magazine, 2018, 21(1): 34-43.

https://doi.org/10.1109/MIM.2018.8278808

8. Botti A, Monda A, Pellicano M and Torre C. The re-conceptualization of the port supply chain as a smart port service system: the case of the port of Salerno. Systems, 2017, 5(2): 35.

9. Zavadskas E K, Turskis Z, Vilutienè T and Lepkova N. Integrated group fuzzy multi-criteria model: Case of facilities management strategy selection. Expert Systems with Applications, 2017, 82: 317-331. https://doi.org/10.1016/j.eswa.2017.03.072

10. Kaplan R S. Conceptual foundations of the balanced scorecard. Handbooks of management accounting research, 2009, 3: 1253-1269.

11. Bobillo F, Delgado M, Gómez-Romero J and López E. A semantic fuzzy expert system for a fuzzy balanced scorecard. Expert Systems with Applications, 2009, 36(1): 423-433.

12. Fernández P, Santana JM, Ortega S, Trujillo A, Suárez JP, Domínguez C, Santana J and Sánchez A. SmartPort: A Platform for Sensor Data Monitoring in a Seaport Based on FIWARE. Sensors, 2016, 16: 417. https://doi.org/10.3390/s16030417

13. Durán C A, Córdova F M and Palominos F. A conceptual model for a cyber-social-technological-cognitive smart medium-size port. Procedia Computer Science, 2019, 162: 94-101

14. Zadeh L A. The role of fuzzy logic in the management of uncertainty in expert systems. Fuzzy sets and systems, 1983,11(1-3): 199-227

15. Kaufmann A and Gupta M M. Fuzzy mathematical models in engineering and management science. Elsevier Science Inc. 1988

16. Naveed, Quadri Noorulhasan, et al. "Evaluating and ranking cloud-based e-learning critical success factors (CSFs) using combinatorial approach." IEEE Access 7 (2019): 157145-157157. https://doi.org/10.1109/ACCESS.2019.2949044 